$$
\text { CONF- } 970902-1
$$

[Paper for the $21^{\text {st }}$ International Symposium on the Scientific Basis for Nuclear Waste Management, held in Davos, Switzerland, Sept. 28 ${ }^{\text {th }}$ to Oct. 3, 1997]

\title{
19980219069
}

\section{Fundamental Science of f-Elements in Selected Immobilization Glasses: Significance for TRU Disposal Schemes.}

\section{R. G. Haire ${ }^{1}$, Z. Assefa ${ }^{1}$ and N. Stump ${ }^{2}$}

'Oak Ridge National Laboratory, Chemical and Analytical Sciences Division, P. O. Box 2008, MS-6375, Oak Ridge, TN 37831, USA

${ }^{2}$ Dept. Of Physical Science, Winston-Salem State University, 601 Martin Luther King, Jr. Drive, Winston-Salem, NC 27110, USA

$\left[{ }^{*}\right.$ Research sponsored by the Division of Chemical Sciences, Office of Basic Energy Sciences, US Dept. of Energy, under contract DE-ACO5-96OR22464 with Oak Ridge National Laboratory, managed by Lockheed Martin Energy Research Corp.] 


\section{DISCLAIMER}

This report was prepared as an account of work sponsored by an agency of the United States Government. Neither the United States Government nor any agency thereof, nor any of their employees, makes any warranty, express or implied, or assumes any legal liability or responsibility for the accuracy, completeness, or usefulness of any information, apparatus, product, or process disclosed, or represents that its use would not infringe privately owned rights. Reference herein to any specific commercial product, process, or service by trade name, trademark, manufacturer, or otherwise does not necessarily constitute or imply its endorsement, recommendation, or favoring by the United States Government or any agency thereof. The views and opinions of authors expressed herein do not necessarily state or reflect those of the United States Government or any agency thereof. 
Fundamental Science of f-Elements in Selected Immobilization Glasses: Significance for TRU Disposal Schemes.

\author{
R. G. Haire', Z. Assefa ${ }^{1}$ and N. Stump ${ }^{2}$ \\ 'Oak Ridge National Laboratory, Chemical and Analytical Sciences Division, P. O. Box 2008, \\ MS-6375, Oak Ridge, TN 37831, USA \\ ${ }^{2}$ Dept. Of Physical Science, Winston-Salem State University, 601 Martin Luther King, Jr. Drive, \\ Winston-Salem, NC 27110, USA
}

\begin{abstract}
We have investigated certain aspects of the fundamental chemistry and materials science of the $4 \mathrm{f}$ - and $5 \mathrm{f}$-elements in three glass matrices. Two of these matrices were high-temperature $\left(850^{\circ}\right.$ and $1450^{\circ} \mathrm{C}$ melting points) silicate-based glasses and the third was a sol-gel glass. Optical spectroscopy was the principle investigating tool. A primary aspect of this work was to ascertain the oxidation state exhibited by the elements in the different glasses, as well as the factors that control and/or may alter this state. An important finding has been that we have noted a general correlation between the oxidation states obtained in the two high-temperature glasses and their high-temperature oxide chemistries. Of the twenty three f-elements considered here, only a few exceptions ( $\mathrm{Am}$ and $\mathrm{Bk}$ ) or variations ( $\mathrm{Ce}, \mathrm{Pr}, \mathrm{Tb}, \mathrm{U}, \mathrm{Cf}$ ) to this correlation have been noted. Explanations are offered for these cases. The correlation also applied to the sol-gel glasses after heating to $>400{ }^{\circ} \mathrm{C}$, but other oxidation states of certain f-elements could be retained in the unheated glasses prepared by the sol-gel approach. Presented here is a summary of the oxidation states observed for these elements in the three glass matrices and how these states correlate with those observed in their high-temperature oxides.
\end{abstract}

\title{
INTRODUCTION
}

The science of immobilization materials for nuclear waste has been an active topic for decades and many widely-varying studies have been performed regarding this subject. The Materials Research Society itself has held several symposia on this topic dating back to the late seventies, which have highlighted a variety of materials and topics. Studies have varied from examining the different physical properties of the materials to sophisticated attempts to model their long-term behaviors. The latter are frequently given in time frames of up to $10^{6}$ years, which exceed experimental abilities; therefore, some estimation of performance, as modeling, must be considered. Certainly the chemistries of the materials in the different matrices, controlled by electronic configurations and energetics, must be known and carefully considered in modeling performance criteria (e.g., leaching, diffusion, compound stability, etc.). Although we are not involved in such modeling, our experimental efforts have been to address and acquire information about the fundamental chemistry and materials science of the f-elements in different host materials (glasses, inorganic ceramics, etc.). Our goal is to understand this science for both series of f-elements in terms of their changing electronic configurations.

The objective of this phase of the work was to pursue certain aspects of the fundamental solid-state chemistry and materials science of $4 \mathrm{f}$ - and $5 \mathrm{f}$-elements in selected glasses. The determination of their oxidation states, factors that control and/or alter these states, the local environment, coordination and bonding of the metal ions in the hosts, were all primary targets. 
Glasses studied to date have included two high-temperature $\left(850^{\circ}\right.$ and $1400^{\circ} \mathrm{C}$ melting points) silicate-based glasses and a glass prepared via a sol-gel technique that involved hydrolysis of a organic silicate. Optical spectroscopy (absorbance, fluorescence, Raman) was the principal investigating tool, although other techniques have also been employed. As these glasses are generally transparent, spectroscopy has been a viable method for establishing the oxidation states of the $\mathrm{f}$-elements in these glasses.

Addressed here are the oxidation states attained by the individual f-elements in the three glasses. We have examined the lanthanides from $\mathrm{La}$ through $\mathrm{Lu}$ (except for $\mathrm{Pm}$ ) and the actinides from $\mathrm{Np}$ through Es. Although the shorter lived transcurium isotopes (which only exist in limited quantities) are not candidates for wastes, they have been studied in these glasses as their half-lives and mode of radio-decay make them attractive for probing certain issues (effects of radiation, chemistry of the progeny formed in-situ, etc.). Results of this work will be published in the future.

With the two silicate glasses prepared at high temperatures, we have noted that a correlation exists between the oxidation state of the f-element obtained in the glass products and the elements' high-temperature oxide chemistries. Of the f-elements considered for this correlation, two exceptions ( $\mathrm{Am}, \mathrm{Bk})$ were noted, two elements $(\mathrm{Ce}, \mathrm{U})$ showed variable oxidation states and three $(\mathrm{Pr}, \mathrm{Tb}$ and $\mathrm{Cf})$ displayed a minor deviation. In general, the correlation seemed plausible given that silica-based networks are encountered in the glasses and that the glasses were prepared in air. These exceptions are addressed by considering factors that affect the oxidation state observed.

The chemistries of these elements in the sol-gel system is considered in two stages; first in the gel state and secondly in the final silicate matrix. In the glasses formed by this sol-gel technique, materials should, in principle, be homogeneously dispersed and uniformly bonded without undergoing the high temperatures encountered in the molten glass dissolution. Thus, by preparing sol-gel glasses, several aspects of the f-elements' chemistries, including their oxidation states, can be explored: (1) without encountering the higher temperatures required for synthesis; and (2) as a function of subsequent heating. With this approach, glasses can be obtained that contain oxidation states of certain elements (e.g., those of $\mathrm{Np}$ or $\mathrm{Pu}$ ) which cannot be obtained via dissolution of the materials in the molten glasses.

We present here the results of our survey of the oxidation state behavior of twenty-three $f$ elements in these glass matrices and how these states correlate with the those found in their oxides. In addition, the oxidation state behaviors of these elements in the sol-gel glasses are compared with those in the melted glasses.

\section{EXPERIMENTAL}

\section{$\underline{\text { Materials }}$}

The lanthanide oxides (high temperature glass preparations) and nitrates (sol-gel preparations) used in these studies were obtained as commercial products (REC 99.99\%) and used directly in preparing the glass products. The transuranium materials were obtained through the U.S. Department of Energy's (DOE) programs, and were of comparable purity. These isotopes were also employed as oxides and dilute $\mathrm{HNO}_{3}$ solutions. The following actinide isotopes were employed: Np-237; Pu-242; Am-243; Cm-248; Bk-249, Cf-249 and Es-253. 
Many of these isotopes were products of the High Flux Isotope Reactor, located at Oak Ridge National Laboratory.

Two high-temperature glass formulations were used in this work. One was a higher-melting material $\left(1450{ }^{\circ} \mathrm{C}\right)$ having the following nominal weight percentages: $\mathrm{SiO}_{2}(30 \%) ; \mathrm{B}_{2} \mathrm{O}_{3}(6 \%)$; $\mathrm{BaO}(3 \%) ; \mathrm{Al}_{2} \mathrm{O}_{3}(13 \%) ; \mathrm{PbO}(10 \%)$; and f-element (38\%). To allow a variation of the f-element being examined (for optimizing the spectroscopy) while maintaining a constant f-element content, lanthanum was added to maintain a $38 \%$ f-element composition. Components without the f-elements were first melted to form a stock glass; solidified by cooling; and ground to provide a stock. Portions of this base was then ground with the desired quantity of f-element oxide and this mixture melted at $1450^{\circ} \mathrm{C}$ in a micro-Pt container. After complete dissolution (48 hours), the material was slowly cooled to room temperature. The products were obtained in the form of small, transparent glass "jewels" of different colors.

The second formulation was a lower-melting $\left(850{ }^{\circ} \mathrm{C}\right)$ glass with the following nominal weight percentages: $\mathrm{SiO}_{2}(50 \%) ; \mathrm{B}_{2} \mathrm{O}_{3}(18 \%) ; \mathrm{Na}_{2} \mathrm{O}(24 \%) ; \mathrm{CaO}(3 \%)$ and the f-element (5\%). The components without the f-element were melted and after cooling, ground to serve as a base for subsequent glass preparations. The f-element samples were prepared by melting a portion of this glass base in a mirco- Pt container at $850{ }^{\circ} \mathrm{C}$ and then dissolving the appropriate amount of the f-element oxide in the glass. The container allowed observation of the dissolution process. After dissolution was complete (verified by microscopic observation), the material was slowly cooled to room temperature. The final products were similar in appearance to the products prepared at $1450^{\circ} \mathrm{C}$.

The sol-gel glasses were prepared by mixing $0.1 \mathrm{M}$ f-element- $0.5 \mathrm{M} \mathrm{HNO}$ solutions with equal volumes of methanol and tetramethylorthosilicate in small Pyrex cylinders, which had restricted openings to depress volatilization of the components. After 24-48 hours, transparent, solid "glasses" (solid gels with residual volatile components) were formed, which could be removed as single pieces from the Pyrex cylinders. To remove the encapsulated volatile components, it was necessary to heat these gel products to elevated temperatures (e.g., $800{ }^{\circ} \mathrm{C}$ ) to form a true silica-type matrix.

\section{Spectroscopy}

Portions of each glass product were taken and sealed in quartz tubes with optically-flat sides designed in-house for our spectroscopic measurements. Different spectroscopic instruments were employed in the work, including those equipped with microscopic attachments for smaller samples containing the scarcer elements. The primary instrument was a Jobin Yvon/Instruments SA model Ramanor HG.2S spectrometer (resolution $0.5 \mathrm{~cm}^{-1}$ at $514 \mathrm{~nm}$ ) employed in conjunction with a microscopic attachment (Nachet, model NS-400). For absorption studies, a xenon-arc lamp was used and the dispersed light measured via a photon counting system (cooled photomultipler; multichannel analyzer) interfaced with a PC computer using Galactic Industries, "Spectra-Calc" software. Fluorescence measurements were made using many of the above components but employing a 5 watt argon laser (usually at reduced power levels to avoid excessive heating of the samples) by the excitation source.

\section{RESULTS AND DISCUSSION}

Solid-state spectroscopy was the primary tool used to investigate the oxidation states attained for a large number of $\mathrm{f}$-elements in the three different glass matrices. The main objective in the 
work reported here was to survey the oxidation state and chemistry of individual f-elements in these immobilization hosts, as a function of preparation and treatment. A second goal was to understand this behavior in terms of the electronic configurations and known chemistry of each element. The correlation noted between the oxidation state of the f-element in the different glass products with that in its oxide system achieved the second goal. In this initial work, the intent was to consider two glass formulations, and to avoid the presence of materials that may afford a redox couple with the f-element being studied. Given the space limitations here, we have avoided an extensive review of other work and the presentation of spectroscopic data, which will appear in detail in other publications.

The oxide systems of the f-elements are complex, dependent on several factors, which include crystal systems, packing efficiencies, oxidation potentials and oxygen fugacities of the atmospheres used in their preparation, etc. A brief listing of oxides known for the f-elements are given in Table I for understanding the basis used for the correlation between elements' behaviors in oxides and in the glasses. The reader is referred to a recent review of lanthanide and actinide oxides for more comprehensive details [1]. The underlined oxides in Table I are those that would be expected after heating in air at $1000{ }^{\circ} \mathrm{C}$. Also shown in this table are the oxidation states observed in the glasses subjected to $>800^{\circ} \mathrm{C}$ (labeled as, "H.T. Glass" in Table I).

TABLE I. Main Oxides of the f-Elements and Oxidation States Observed in Glasses

\begin{tabular}{|c|c|c|c|c|c|}
\hline & Oxide(s) & $\begin{array}{l}\text { State in } \\
\text { H.T. Glass }\end{array}$ & & Oxide(s) & $\begin{array}{c}\text { State in } \\
\text { H.T. Glass }\end{array}$ \\
\hline $\mathrm{La}$ & $\underline{\mathrm{La}}_{2} \underline{\mathrm{O}}_{3}$ & - & $\mathrm{Ac}$ & $\underline{\mathrm{Ac}}_{2} \underline{\mathrm{O}}_{3}$ & - \\
\hline $\mathrm{Ce}$ & $\mathrm{Ce}_{2} \mathrm{O}_{3} ; \mathrm{Ce}_{7} \mathrm{O}_{12} ; \underline{\mathrm{CeO}_{2}}$ & III; IV & $\mathrm{Th}$ & $\underline{\mathrm{ThO}}_{2}$ & IV \\
\hline $\operatorname{Pr}$ & $\mathrm{Pr}_{2} \mathrm{O}_{3} ; \underline{\operatorname{Pr}}_{6} \underline{\mathrm{O}}_{11} ; \mathrm{PrO}_{2}$ & III & $\mathrm{Pa}$ & $\mathrm{PaO}_{2} ; \underline{\mathrm{Pa}}_{2} \underline{\mathrm{O}}_{5}$ & - \\
\hline $\mathrm{Nd}$ & $\underline{\mathrm{Nd}}_{2} \underline{\mathrm{O}}_{3-}$ & III & $\mathrm{U}$ & $\mathrm{UO}_{2} ; \mathrm{U}_{4} \mathrm{O}_{9} ; \underline{\mathrm{U}}_{3} \underline{\mathrm{O}}_{8} ; \mathrm{UO}_{3}$ & IV; V, VI \\
\hline $\mathrm{Pm}$ & $\underline{\mathrm{Pm}}_{2} \underline{\mathrm{O}}_{3}$ & - & $\mathrm{Np}$ & $\underline{\mathrm{NpO}}_{2} ; \mathrm{Np}_{2} \mathrm{O}_{5}$ & IV \\
\hline $\mathrm{Sm}$ & $\mathrm{SmO} ; \underline{\mathrm{Sm}}_{2} \underline{\mathrm{O}}_{3}$ & III & $\mathrm{Pu}$ & $\mathrm{Pu}_{2} \mathrm{O}_{3} ; \mathrm{PuO}_{2}$ & IV \\
\hline $\mathrm{Eu}$ & $\mathrm{EuO} ; \mathrm{Eu}_{3} \mathrm{O}_{4} ; \underline{\mathrm{Eu}}_{2} \underline{\mathrm{O}}_{3}$ & III & $\mathrm{Am}$ & $\mathrm{Am}_{2} \mathrm{O}_{3} ; \mathrm{Am}_{7} \mathrm{O}_{12} ; \underline{\mathrm{AmO}_{2}}$ & III \\
\hline Gd & $\underline{\mathrm{Gd}}_{2} \underline{\mathrm{O}}_{3}$ & III & $\mathrm{Cm}$ & $\underline{\mathrm{Cm}}_{2} \underline{\mathrm{O}}_{3}, \mathrm{Cm}_{7} \mathrm{O}_{12} ; \mathrm{CmO}_{2}$ & III \\
\hline $\mathrm{Tb}$ & $\mathrm{Tb}_{2} \overline{\mathrm{O}}_{3} ; \underline{\mathrm{Tb}}_{7} \underline{\mathrm{O}}_{12} ; \mathrm{TbO}_{2}$ & III & $\mathrm{Bk}$ & $\mathrm{Bk}_{2} \mathrm{O}_{3} ; \underline{\mathrm{BkO}}_{2}$ & III \\
\hline Ho & $\underline{\mathrm{Ho}}_{2} \underline{\mathrm{O}}_{3-}$ & III & $\mathrm{Cf}$ & $\mathrm{Cf}_{2} \mathrm{O}_{3} ; \mathrm{Cf}_{7} \underline{\mathrm{O}}_{12} ; \mathrm{CfO}_{2}$ & III \\
\hline Dy & $\underline{\mathrm{Dy}}_{2} \underline{\mathrm{O}}_{3}$ & III & Es & $\underline{E S}_{2} \underline{\mathrm{O}}_{3}$ & III \\
\hline Er & $\underline{\mathrm{Er}}_{2} \underline{\mathrm{O}}_{3}$ & III & $\mathrm{Fm}$ & - & - \\
\hline $\mathrm{Tm}$ & $\underline{\operatorname{Tm}}_{2} \underline{\bar{O}}_{3}$ & III & $\mathrm{Md}$ & - & - \\
\hline $\mathrm{Yb}$ & $\mathrm{YbO} ; \underline{\mathrm{Yb}}_{2} \underline{\mathrm{O}}_{3}$ & III & No & - & - \\
\hline $\mathrm{Lu}$ & $\underline{\mathrm{Lu}}_{2} \underline{\mathrm{O}}_{3}$ & III & $\mathrm{Lr}$ & - & - \\
\hline
\end{tabular}

During our investigations of the lanthanides in the three glass matrices, we observed only the trivalent state except for the case of cerium. With Ce, both $\mathrm{Ce}$ (III) and Ce (IV) were observed but it is not straight forward to differentiate between these two states by spectroscopy (either absorption and/or emission). Slight shifts in characteristic absorption envelopes due to complexation or other reasons, or broadening of the envelopes, reduce the ability to resolve unequivocally between these two states. It was clear that Ce (IV) was the major state in the glasses after high-temperature treatment in air. Other workers have reported both $\mathrm{Ce}$ (III) and . 
$\mathrm{Ce}(\mathrm{IV})$ in glass materials using different analytical approaches [2-5]. Since Ce(IV) is one state observed in the glasses, rather than Ce being an exception to the correlation, it merely displays a variable behavior. In Ce glasses prepared by the sol-gel technique, different colors were observed (which indicated reduction of $\mathrm{Ce}$ (IV) as well as oxidation of $\mathrm{Ce}$ (III)) were encountered at different stages, when using different starting materials (e.g., $\mathrm{Ce}$ (III) or $\mathrm{Ce}$ (IV)) in the preparations. Studies involving $\mathrm{Ce}$ in the sol-gels are being pursued further.

Observing only the trivalent state for the other lanthanides in the glasses is in full accord with their oxide behaviors, except for the cases of $\mathrm{Pr}$ and $\mathrm{Tb}$. Both elements produce oxides in air that formally are greater than trivalent but less than tetravalent. Their dioxides require special preparative conditions and are not thermally stable over $400{ }^{\circ} \mathrm{C}$. In most of their chemistries these two elements are trivalent. The observation of a higher state in oxides is due in part to the stabilization afforded by a cubic oxide lattice (see later section). This same affect is encountered to an even greater extent with $\mathrm{Am}$ and $\mathrm{Bk}$ oxides and to a similar degree with $\mathrm{Cf}$..

With respect to the $\mathrm{Ac}, \mathrm{Th}$, and $\mathrm{Pa}$ in glasses, to our knowledge there has been no studies of $\mathrm{Ac}$ or $\mathrm{Pa}$ in glasses. Ac should behave exactly like La, and be trivalent. Pa posses a different and interesting case. Our speculation is, based on the nature of Pa chemistry and the affinity of this element for oxygen, that $\mathrm{Pa}$ would exist in its pentavalent state in the glasses but could be retained in a tetravalent state. Both states would be in accord with those in known oxides. With respect to Th, other workers have examined it in glasses and found that Th (IV), as would be expected, is observed [6].

The incorporation of $U$ into glasses has been pursued by many workers who have found oxidation states of (III) to (VI) [7-10]. U is also unique in its oxide chemistry, displaying a number of oxides and is the actinide that forms the highest binary oxide $\left(\mathrm{UO}_{3}\right)$. The latter has limited thermal stability but yet U(VI) is observed in glasses. U(IV) is also a well-known state for $U$ in glasses, although its dioxide is readily converted to higher oxides by heating in air. The nature of how $\mathrm{U}$ exists in the glasses is important: U(IV) has limited solubility in the glass and may precipitate out as $\mathrm{UO}_{2}$; in contrast, $\mathrm{UO}_{2}{ }^{2+}$ is dispersed and incorporated differently in the silicate network. An interesting aspect is that $\mathrm{U}(\mathrm{V})$ can be formed by photo-reducing $\mathrm{U}(\mathrm{VI})$ in a glass. Thus, $\mathrm{U}$ may be considered as existing principally as $\mathrm{U}(\mathrm{IV})$ or $\mathrm{U}(\mathrm{VI})$ in glasses; as $\mathrm{U}_{3} \mathrm{O}_{8}$ is an air stable oxide formally containing both U(IV) and U(VI), the display of these two states in glasses is not too surprising.

Our investigations with the elements, $\mathrm{Np}$ through Es, in glasses were more extensive than those with the lanthanides. We also studied these elements in the two high-temperature glasses and in the sol-gel generated glass. A special aspect of the work with $\mathrm{Np}$ and $\mathrm{Pu}$ was that we were able to incorporate oxidation states of $\mathrm{Np}$ and $\mathrm{Pu}$ besides their tetravalent state (the only state found with the molten glass preparations) using the sol-gel technique at ambient temperature. It was then possible to follow the stability of these other states as a function of heating up to $850^{\circ} \mathrm{C}$

In work on $\mathrm{Np}$ glasses, we observed only $\mathrm{Np}$ (IV) in the high-temperature molten glass preparations and in sol-gel glasses that had been heated to over $400{ }^{\circ} \mathrm{C}$. This is in accord with $\mathrm{NpO}_{2}$ being the high-temperature binary oxide for $\mathrm{Np}$. Other workers have also observed $\mathrm{Np}$ (IV) in glass matrices $[9,10]$, although one report claimed the presence of $\mathrm{Np}(\mathrm{III})$ when graphite was available as a reductant [11]. The latter state is difficult to achieve with $\mathrm{Np}$, and is not found in a 
binary oxide of $\mathrm{Np}$. In our studies with sol-gel glasses, it was possible to prepare sol-gel products containing $\mathrm{Np}(\mathrm{IV}), \mathrm{Np}(\mathrm{V})$ and $\mathrm{Np}(\mathrm{VI})$ at room temperature, when starting with these oxidation states in aqueous media [12]. We were not able to prepare a $\mathrm{Np}$ (III) product in this manner. However, when these room temperature sol-gel products were heated above $400{ }^{\circ} \mathrm{C}$, only $\mathrm{Np}$ (IV) remained in the glass, again consistent with the behavior of $\mathrm{Np}$ in oxides.

We observed a similar situation for Pu. We observed only $\mathrm{Pu}$ (IV) in glasses prepared in molten glass and in sol-gel glasses that had been heated above $400{ }^{\circ} \mathrm{C}$. It was possible to incorporate either $\mathrm{Pu}$ (III), $\mathrm{Pu}$ (IV) or $\mathrm{Pu}$ (VI) in the room temperature sol-gel glasses by starting with these states in the aqueous solutions employed in preparing the sol-gel glasses; upon subsequent thermal treatments, first the III state $\left(<200^{\circ} \mathrm{C}\right)$ and then the VI state $\left(>400{ }^{\circ} \mathrm{C}\right)$ were converted to $\mathrm{Pu}(\mathrm{IV})$ [12]. Other workers have also reported $\mathrm{Pu}$ (IV) as the state obtained in glass products prepared at elevated temperatures $[9,10]$. From the $\mathrm{Pu}$ oxide system, $\mathrm{Pu}$ (IV) would be the expected oxidation state in the glasses after high-temperature treatment.

Am is one of the interesting cases with regard to which oxidation would be expected in the glass products. $\mathrm{AmO}_{2}$ is the air stable oxide and is readily obtained when a variety of Am salts are heated in air. It is known that its dioxide starts to lose oxygen at elevated temperatures (e.g., in air at $>1000{ }^{\circ} \mathrm{C}$ [1]). However, $\mathrm{Am}_{2} \mathrm{O}_{3}$ at room temperature will also take-up oxygen to approach the stoichiometry of the dioxide. This suggests that Am (IV) should be found in the glasses but experimentally, only Am (III) was observed by us [13 ] and by other workers [9,10]. Dissolution of $\mathrm{AmO}_{2}$ in the molten $850^{\circ} \mathrm{C}$ glass evolved oxygen and yielded a pink glass, a color characteristic of Am (III) with limited complexation/coordination (e.g., Am (III) in dilute $\mathrm{HCl}$ is pink and yellow in stronger $\mathrm{HCl}$ ). The rationale for obtaining Am (III) rather than Am (IV) is discussed in a later section and involves the stability afforded by the fluorite dioxide structure.

With $\mathrm{Cm}$, we observed only the trivalent state in the glasses. This observation is fully in line with the electronic configuration of $\mathrm{Cm}\left([R n\right.$ core $\left.] 5 \mathrm{f}^{7} 6 \mathrm{~d}^{1} 7 \mathrm{~s}^{2}\right)$, which stabilizes the trivalent state. Surprisingly, $\mathrm{Cm}$ forms a dioxide (in contrast to its lanthanide electronic homolog, $\mathrm{Gd}$, due to the greater spatial extension of the $5 \mathrm{f}$ versus the $4 \mathrm{f}$ orbitals) but this compound has limited thermal stability $\left(<350^{\circ} \mathrm{C}\right.$ in air $)$.

The remaining three actinide elements studied, $\mathrm{Bk}, \mathrm{Cf}$ and $\mathrm{Es}$, are not likely candidates for incorporation into wastes. Rather, glasses containing these elements are of interest for understanding their chemistry and materials science in such hosts. These products also provide an opportunity to study decay profiles in the glass host (e.g., to follow radiation effects, oxidation states and local environment of the daughter and grand-daughter progeny).

The general oxidation state behavior of $\mathrm{Bk}$ should be similar to that of $\mathrm{Ce}$, but in studies to date we have observed only Bk (III) in the glasses. The reason should be considered in the same context as for the behavior of Am; in terms of added stability provided by the cubic oxide lattice (see a later section). We also observed only Cf (III) in the glass products. This is more in accord with that expected from the Cf oxygen system, and viewed in the same manner as the behaviors of $\mathrm{Pr}$ and $\mathrm{Tb}$ in these glasses. There are many similarities between the $\mathrm{Tb}$ and $\mathrm{Cf}$ binary oxides, including the limited thermal stability of their higher oxides [1]. With regards to Es, only Es (III) was observed in a $850^{\circ} \mathrm{C}$ glass (the only Es glass studied to date), which is fully in line with formation of a single oxide, $\mathrm{Es}_{2} \mathrm{O}_{3}$. The studies involving the decay profile of Es 
(Es- $\alpha \rightarrow$ Bk- $\beta \rightarrow \mathrm{Cf}$ ) in this glass matrix are beyond the scope of the present paper and will be published separately.

Stability Provided by the Fluorite Lattice

The lanthanide and actinide trivalent oxide systems have similarities, including common hightemperature sesquioxide structures/phase behaviors and fluorite-type dioxides. One sesquioxide phase is a body centered cubic (bcc; $\alpha-\mathrm{Mn}_{2} \mathrm{O}_{3}$ type structure), which can readily take up oxygen to eventually produce a stable dioxide that exhibits a fluorite-type structure. This bcc lattice has vacancies that can be filled by oxygen at room temperature to yield higher oxides up to the dioxide. During dissolution of the dioxide in a molten glass, stability afforded by this fluorite lattice is lost and the elements revert to their preferred trivalent states, which is then maintained in the glasses. Interestingly, for more stable dioxides, inclusion or precipitation of the dioxides rather than dissolution may be observed. This lattice stability may account for the difference between oxidation states observed in glasses and in oxides for the f-elements. This explanation would be appropriate for $\mathrm{Am}$ and $\mathrm{Bk}$, which normally form stable dioxides in air; for $\mathrm{Cm}$, which has only a limited dioxide stability; and also for $\mathrm{Pr}, \mathrm{Tb}$ and $\mathrm{Cf}$, which can partially oxidize to intermediate binary oxides during heating in air but frequently exhibit a trivalent state in other chemistries.

\section{Consideration of Oxidation Potentials}

Oxidation potentials for these elements in glasses, and the oxygen fugacity in the glasses during preparation at high temperatures, are difficult to evaluate experimentally. By using reported oxidation potentials [14] as pseudo potentials for f-elements in glasses (but only for relative comparisons), a better feeling for their oxidation states may be acquired. This approach, and considering the lattice stability, can provide some rational for whether a trivalent or tetravalent (or higher) state of may be expected in the glasses. In Figure 1 are shown pseudo potentials for this approach, where an arbitrary line is drawn through the $\mathrm{Ce}$ and $\mathrm{Bk}$ points (elements below the line, trivalent; above the line, at least tetravalent). Am is the closest to (just below) this line but was unquestionably trivalent in the glasses studied. With $\mathrm{Ce}$ and $\mathrm{Bk}$, a variable valence should be expected. The difference observed between $\mathrm{Ce}$ and $\mathrm{Bk}$ glasses (Ce favoring the (IV) state; Bk the (III) state) was not anticipated and the Figure 1. Pseudo Oxidation Potentials for f-Elements point will be a target of additional studies. One aspect to be considered with Bk-249 is its $\beta$ radiation (3.64 X $\left.10^{9} \mathrm{dis} \mathrm{min}^{-1} \mu \mathrm{g}^{-1}\right)$ and whether it may influence the valence of $\mathrm{Bk}$ in the glass matrix.

\section{Conclusion/Summary}

The goal of the present effort was to survey the chemical behavior of several individual $\mathrm{f}$ elements in three glass matrices, with the intent of acquiring a better understanding of the materials science of these systems. Two general glass compositions were chosen: one with a 
modest melting temperature $\left(850^{\circ} \mathrm{C}\right)$ and the other with a higher melting temperature $\left(1450{ }^{\circ} \mathrm{C}\right)$. The presence of reducing and oxidizing agents were avoided purposely in this phase of our studies. A sol-gel technique was also employed for preparing glasses at room temperatures, which avoided the elevated high-temperatures involved in the molten preparations. The solid gel products at $25{ }^{\circ} \mathrm{C}$ retained volatile components until heated to elevated temperatures. One special aspect of these materials was that more than one oxidation states of some f-elements could be inserted in the gel matrix, which permitted us to follow the stability of different oxidation states in the matrix as a function of subsequent heating.

A progression in this effort was to develop rationale for the observed findings, and this resulted in noting that a correlation existed between the oxidation states observed for these elements in glasses and the states expected from their oxide chemistry. Exceptions and/or variations were noted for a few of the elements but these could be rationalized, when certain aspects of lattice stabilization and/or pseudo oxidation potentials for these elements were considered. It must be realized that other glass formulations, the presence of other materials that may influence or introduce redox couples, incorporating multiple f-elements as well as other factors must be considered in further work to acquire a more complete understanding of these glass systems.

\section{ACKNOWLEDGMENT}

[Research sponsored by the Division of Chemical Sciences, Office of Basic Energy Sciences, US Dept. of Energy, under contract DE-ACO5-960R22464 with Oak Ridge National Laboratory, managed by Lockheed Martin Energy Research Corp. The transuranium isotopes were made available through the BES program at ORNL's production facilities. One of us (NAS) was supported through the ORISE program at Oak Ridge ]

\section{REFERENCES}

1. R. G. Haire and L. Eyring, in Handbook on the Physics and Chemistry of Rare Earths, Vol.

18. Lanthanides/Actinides: Chemistry, edited by K. A. Gschneidner, Jr., L. Eyring, G. R.

Choppin and G. H. Lander (North-Holland, New York, 1994) pp.413-505.

2. W. D. Johnson, J. Am Ceram. Soc.,48,184(1965).

3. M. Leskela and J. Su-Kkanen, J. Less-Common Metals, 112,71(1985).

4. E. M. Larson, F. W. Lytle, P. G. Eller, R. B. Greegar and M. P. Eastman, J. Non-Cryst. Solids, 116,57(1990).

5. A. Paul, M. Mulhollard and M. S. Zamar, J. Mat. Sci., 11,2082(1976).

6. F. Farger, Cosmochemica 55,3303(1991).

7. H. D. Schreiber, G. Bryan Balazr and Barbara J. Williams, J. Am. Ceramic Soc., 65,449(1982).

8. H. D. Schreiber, J. Less-Common Metals 91,129(1983).

9. D. G. Karraker, J. Am. Ceram. Soc.,65,53(1982).

10. P. G. Eller,G. D. Jarvinen, J. D. Purson, R. A. Penneman, R. R. Ryan, F. W. Lytle and R. B. Greegor, Radiochimica Acta, 39,17(1985).

11 I. S. Muller, J. Non-Crystall. Solids, 134,147(1991).

12. N.A. Stump, R. G. Haire and S. Dai, Mat. Res. Soc. Proc., Vol 465, editors Wm. J. Gray and I.R. Triay, (MRS , Penn,1997) pp.47-54.

13. R. G. Haire and N. A. Stump, Mat. Res. Soc. Proc., Vol 465, editors Wm. J. Gray and I.R. Triay, (MRS , Penn,1997) pp.39-46.

14. L.J. Nugent, R. D. Baybarz, J. L Burnett and J. R. Ryan, J. Inorg. Nucl. Chem., 


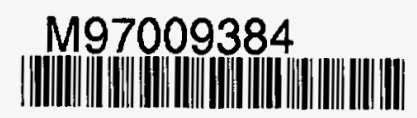

Report Number (14)CONF-970902- -

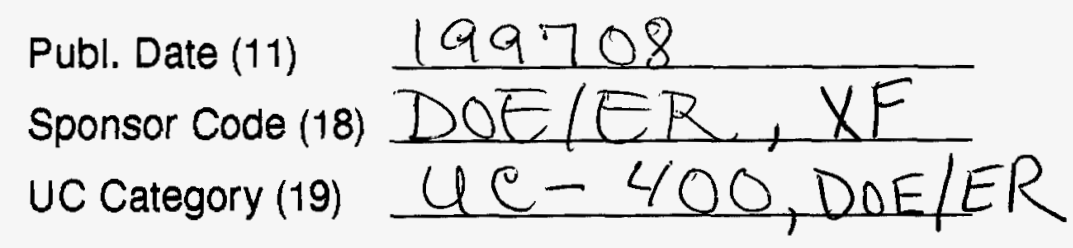

